\title{
The surgical treatment of restrictive cardiomyopathy in pseudoxanthoma elasticum
}

\author{
V F CHALLENOR, N CONWAY, J L MONRO \\ Wessex Regional Cardiothoracic Unit, Southampton General Hospital
}

SUMMARY A patient with pseudoxanthoma elasticum presented in pulmonary oedema with $\mathcal{C}_{\mathrm{N}}^{\complement}$ restrictive left ventricular cardiomyopathy caused by calcified endocardial bands that were confirmed on echocardiography and at catheterisation. The bands were resected as far as possible and the involved mitral valve was replaced by a heterograft. A year later calcification of the 3 heterograft forced its replacement by a St Jude prosthesis. Relief of symptoms has been good in the medium term.

\section{Case report}

A 27 year old white man, known to have pseudoxanthoma elasticum, presented with a rapidly progressive nine month history of exertional dyspnoea, orthopnoea, paroxysmal nocturnal dyspnoea, and the striking symptom of exertional haemoptysis. Over the nine month period his exercise tolerance had decreased from that of an active amateur footballer to being unable to walk more than one hundred yards on the flat.

Physical examination showed the classic skin lesions of pseudoxanthoma elasticum-yellow pseudoxanthomatous plaques, mainly in the neck region. There was evidence of congestive cardiac failure, with a sinus tachycardia, a loud left ventricular third heart sound, bilateral basal crepitations, jugular venous pressure raised $3-4 \mathrm{~cm}$ with a deep " $y$ " descent, an enlarged pulsatile liver, and oedema of the legs. The electrocardiogram showed no abnormality and in particular the QRS complexes and $T$ waves were normal. The chest $x$ ray showed considerable calcification within the cardiac outline-in particular in the region of the left ventricle (figure). The classic appearances of pulmonary oedema were present. Cross sectional and $M$ mode echocardiography showed several abnormal features (table 1). The left ventricular endocardium was markedly thickened, particularly in the posterior wall region. There was "flattening" of the left ven-

Requests for reprints to Dr V F Challenor, Department of Cardiology, E Level, Southampton General Hospital, Tremona Road, Southampton SO9 $4 \mathrm{XY}$. tricular posterior wall diastolic motion, although $\vec{\oplus}$ this could not be assessed quantitatively. There $\infty^{\infty}$ appeared to be diastolic restriction of left ventricular 0 filling. The mitral valve E-F slope was at the lower limit of normal and mitral valve excursion was reduced. Left ventricular systolic function appeared to be normal, as shown by a normal ejection fraction $\frac{\varrho}{\propto}$ and left ventricular fractional shortening. Left ven- $\stackrel{-}{\vec{F}}$ tricular systolic and end diastolic internal dimension $\frac{3}{3}$ were within normal limits. The left atrium was markedly enlarged, in keeping with restriction of diastolic filling of the left ventricle in the absence of mitral stenosis. There was minor prolapse of the anterior mitral leaflet. The pericardium appeared to? be of normal thickness. The right ventricle appeared to be normal.

The clinical and echocardiographic findings suggested a diagnosis of a restrictive left ventricular cardiomyopathy secondary to pseudoxanthoma elasticum. To obtain a definitive diagnosis, cardiac? catheterisation was undertaken. Table 2 gives the right and left heart pressures obtained before angio- $N$ graphy. The left ventricular end diastolic pressure was markedly raised at $25-30 \mathrm{~mm} \mathrm{Hg}$. The pulmonary artery and right ventricular pressures were $\omega$ also raised, although the right ventricular endF diastolic pressure was normal. The pulmonarye artery wedge pressure was raised with considerable " $x$ " and " $y$ " descents. Right atrial pressures were normal. There were no valve gradients. Left ventric $\frac{T}{0}$ ular angiography showed a heavily calcified left ven $\frac{\mathrm{D}}{\mathrm{D}}$ tricular endocardium with overall reduction in leff ventricular contractility and a prolonged diastolice phase. There was mild mitral regurgitation. The 

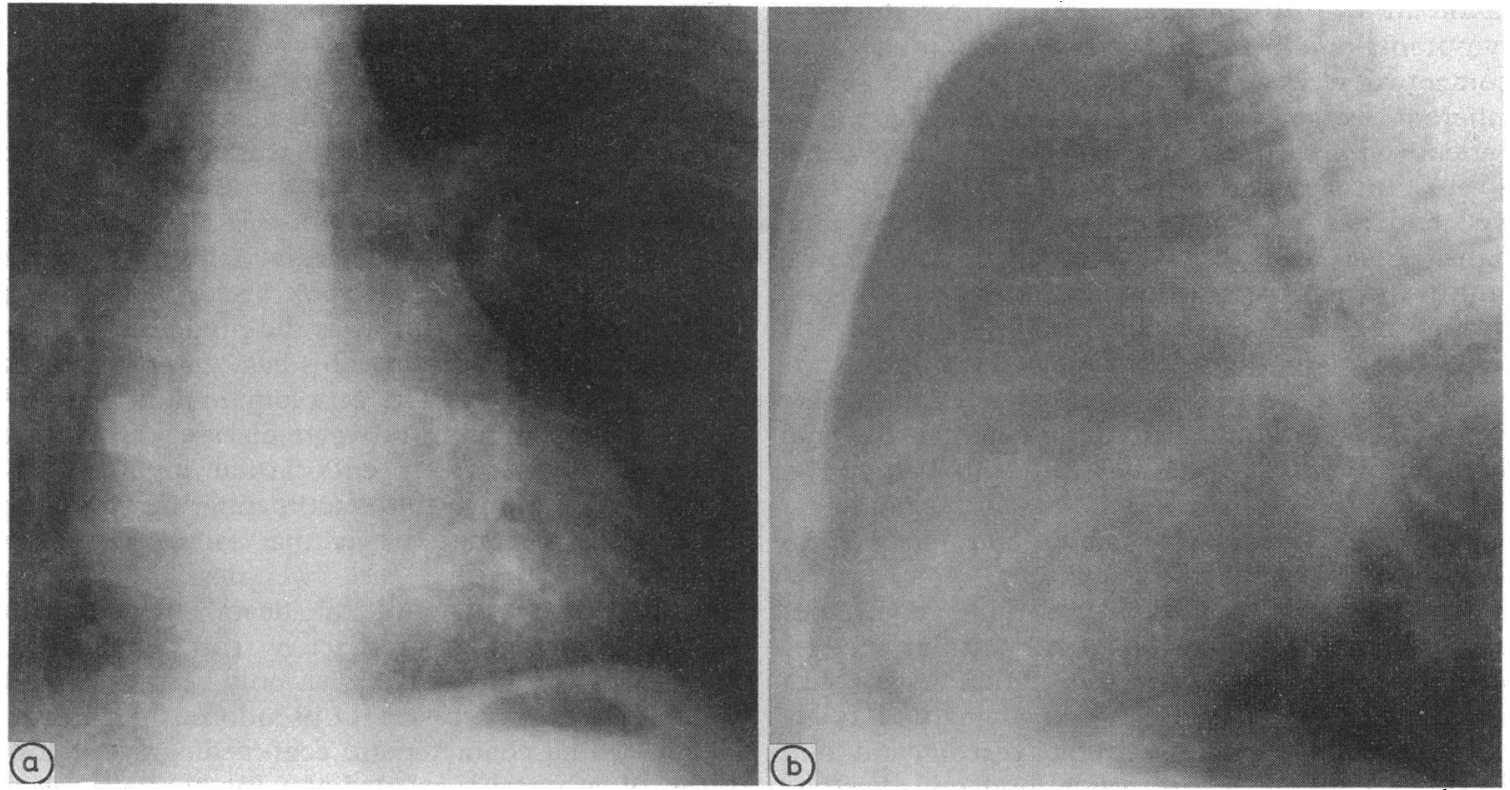

Fig Chest $x$ rays from posterior-anterior $(a)$ and lateral views $(b)$ showing calcification in the region of the left ventricle.

right ventricle contracted normally. Coronary arteriography revealed a solitary stenosis of $40 \%$ beyond the first septal branch of the left anterior descending coronary artery. These findings confirmed our diagnosis of a restrictive cardiomyopathy solely affecting the left ventricle. The only cause appeared to be the extensive, but discrete, bands of endocardial calcification extending into the myocardium which were theoretically amenable to resection. In view of his age and rapidly deteriorating condition it was decided to attempt surgical resection.

At operation the lining of the left ventricle was thickened, fibrous, and mainly calcified, although there seemed to be three distinct ridges of calcified tissue along the posterior wall; the last of these was particularly restricting dilatation of the left ventri-

Table 1 Echocardiographic features before operation

\begin{tabular}{|c|c|c|}
\hline Feature & & Normal limits \\
\hline $\begin{array}{l}\text { Mitral valve E-F slope } \\
\text { Mitral valve excursion } \\
\text { Aortic root diameter } \\
\text { Aortic valve cusp separation } \\
\text { LA internal dimension } \\
\text { Septal thickness (diastole) } \\
\text { Posterior LV wall thickness (diastole) } \\
\text { LV internal dimension (systolic) } \\
\text { LV internal dimension (end diastolic) } \\
\text { Cubed formula LV stroke volume } \\
\text { Ejection fraction } \\
\text { LV fractional shortening }\end{array}$ & $\begin{array}{l}53 \\
1 \cdot 7 \\
2 \cdot 9 \\
2 \cdot 0 \\
5 \cdot 9 \\
1 \cdot 2 \\
1 \cdot 8 \\
2 \cdot 6 \\
4 \cdot 2 \\
57 \\
77 \\
0 \cdot 38\end{array}$ & $\begin{array}{l}(50-120 \mathrm{~mm} / \mathrm{s}) \\
(2 \cdot 0-2.5 \mathrm{~cm}) \\
(2 \cdot 0-3.7 \mathrm{~cm}) \\
(1.6-2.6 \mathrm{~cm}) \\
(1.9-3.8 \mathrm{~cm}) \\
(0.7-1.1 \mathrm{~cm}) \\
(0.7-1.1 \mathrm{~cm}) \\
(2.5-4.1 \mathrm{~cm}) \\
(3.5-5.6 \mathrm{~cm}) \\
(55-95 \mathrm{ml}) \\
(65-75 \%) \\
(0.28-0.41)\end{array}$ \\
\hline
\end{tabular}

LA, left atrium; LV, left ventricle. cle. The calcification was friable and went deeply into the myocardium. The mitral valve leaflets were normal, but the chordae were inserted into calcified papillary muscles. The calcification in the posterior wall and to some extent in the two lateral walls was excised as far as possible.

The mitral valve was replaced with a size $31 \mathrm{Car}-$ pentier-Edwards heterograft in view of the papillary muscle involvement. The coronary artery lesion was not considered to be haemodynamically important.

After operation his general condition improved

Table 2 Catheter findings before and after operation

\begin{tabular}{|c|c|c|}
\hline Vessel or chamber & Pressure $(\mathrm{mm} \mathrm{Hg})$ & $\begin{array}{l}\text { Mean or end } \\
\text { diastolic pressure }\end{array}$ \\
\hline $\begin{array}{l}\text { Right atrium } \\
\text { Right ventricle } \\
\text { Pulmonary artery } \\
\text { PAWP } \\
\text { Left ventricle } \\
\text { Aorta }\end{array}$ & $\begin{array}{ll}r \text { Before operation } \\
\mathrm{a}=2 \cdot 5 & \mathrm{v}=0 \\
\mathrm{x}=-5 & \mathrm{y}=-1 \\
90 / 0 & \\
90 / 30 & \\
\mathrm{a}=30 & \mathrm{v}=35 \\
\mathrm{x}=15 & \mathrm{y}=10 \\
110 / 0 & \\
110 / 60 & \end{array}$ & $\begin{array}{l}\text { Mean }=-1 \cdot 5 \\
\text { EDP 2-5 } \\
\text { Mean }=50 \\
\text { Mean }=20 \\
\text { EDP 23-30 } \\
\text { Mean = 85 }\end{array}$ \\
\hline $\begin{array}{l}\text { Right atrium } \\
\text { Right ventricle } \\
\text { Pulmonary artery } \\
\text { PAWP } \\
\text { Left ventricle } \\
\text { Aorta }\end{array}$ & $\begin{array}{ll} & \text { After } \\
\mathrm{a}=-1 & \mathrm{v}=1 \\
\mathrm{x}=-3 & \mathrm{y}=-3 \\
40 /-6 & \\
32 / 12 & \\
\mathrm{a}=10 & \mathrm{v}=11 \\
\mathrm{x}=9 & \mathrm{y}=8 \\
120 /-5 & \\
120 / 70 & \end{array}$ & $\begin{array}{l}\text { Mean }=20 \\
\text { Mean }=10 \\
\text { EDP } 10\end{array}$ \\
\hline
\end{tabular}

PAWP, pulmonary artery wedge pressure. 
markedly with disappearance of both his abnormal symptoms and physical signs. He was discharged home two weeks after operation. In view of the inherent danger of prescribing anticoagulants to patients with pseudoxanthoma elasticum he was not given anticoagulants. Three months later he was well and had no symptoms or abnormal physical signs. Echocardiography confirmed his clinical improvement. Posterior left ventricular wall motion was normal and there did not seem to be any restriction of diastolic left ventricular filling. Cardiac catheterisation was repeated. Table 2 shows the considerable improvement in left ventricular end diastolic pressure, which had fallen to $10 \mathrm{~mm} \mathrm{Hg}$. Pulmonary artery pressure was correspondingly reduced. Left ventricular angiography showed an overall improvement in contractility.

He subsequently remained well for one year but later presented with a two month history of dyspnoea and orthopnoea. On examination he was once again found to be in pulmonary oedema with bilateral basal crepitations, a sinus tachycardia, and loud third heart sound. There was a loud mid-diastolic murmur at the apex. Cross sectional echocardiography showed that the mitral heterograft was thickened and rigid. The left ventricular filling rate was reduced. Overall left ventricular contractility appeared to be normal. Cardiac catheterisation was again repeated. The left ventricular end diastolic pressure was within normal limits at $5 \mathrm{~mm} \mathrm{Hg}$. There was a gradient of $19 \mathrm{~mm} \mathrm{Hg}$ across the mitral prosthesis. Left ventricular angiography confirmed the continued improvement in left ventricular contractility. The mitral heterograft appeared rigid and immobile. These findings suggested that the return of his symptoms was related to stenosis of the mitral heterograft and not to a recurrence of the restrictive cardiomyopathy.

Further operation was indicated and the mitral heterograft was replaced with a St Jude prosthesis and treatment with anticoagulants was started and continued. His recovery was uneventful and associated with complete loss of all his symptoms. At follow up over the next year he was free of symptoms and leading a normal life.

\section{Discussion}

The rare condition of pseudoxanthoma elasticum, first described by Rigal in 1881, is inherited as an autosomal recessive. ${ }^{1}$ It is a multisystem disorder affecting the skin, mucous membranes, eyes, blood vessels, and heart. The pathogenesis is poorly understood, but there is an important defect in the metabolism and subsequent synthesis of elastic fibres. The resulting elastic tissue, which is abnormal, calcifies and degenerates. ${ }^{2}$

Cardiovascular complications are well documented and include angina pectoris caused by premature coronary artery disease, ${ }^{3}$ with sudden death from acute myocardial infarction, ${ }^{4}$ hypertension, ${ }^{5}$ premature peripheral vascular disease, ${ }^{6}$ mitral valve prolapse, ${ }^{7}$ and congestive cardiac failure. The case ${ }^{\circ}$ we describe had mild coronary artery disease, but $\vec{\circ}$ congestive cardiac failure was the predominant car- $\overrightarrow{\vec{\omega}}$ diovascular complication. This has been reported in $\omega_{\sigma}$ up to $70 \%$ of cases. The aetiology is multifactorial with hypertension, mitral valve disease, myocardial or ischaemia, ${ }^{8}$ and direct endocardial involvement ${ }^{9} \underset{\text { in }}{ }$ implicated, although the exact manner in which the in latter leads to congestive cardiac failure is poorly 8 understood. In the case we describe diffuse $\frac{9}{5}$ endocardial fibrosis and calcificaticn resulted in the development of restrictive cardiomyopathy. TT Restrictive cardiomyopathy has only been described $\frac{\mathbb{O}}{7}$ on one previous occasion in pseudoxanthoma elasticum. ${ }^{10}$ The characteristic echocardiographic fea- $₹$ tures of a restrictive cardiomyopathy have been $\overrightarrow{0}$ described in other infiltrative cardiac disorders $\infty_{\infty}^{\infty}$ including primary cardiac amyloidosis. ${ }^{11}$ These features include a normally sized ventricular cavity with normal ventricular systolic function, "flattening" of ventricular posterior wall motion, ${ }^{12}$ diastolic restriction of ventricular filling, and reduc- $\frac{D}{D}$ tion in the E-F slope of the mitral valve. There is usually considerable endocardial thickening, and the left atrium is enlarged in the absence of mitral valve disease. In our case all of these features affected the left ventricle.

The standard 12 lead electrocardiogram is usually $\Phi$ non-specific, although $T$ wave changes and conducting disturbances have been recorded. The chest $x$ ray is similarly not usually a help in establishing the diagnosis, but calcification was a striking feature $ᄋ$ in our patient. There is little information on the

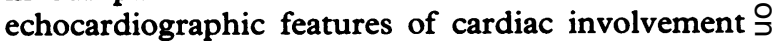
in pseudoxanthoma elasticum, and we believe our $\rightarrow$ report to be the first to describe echocardiographic features of a restrictive cardiomyopathy in this $N$ condition.

Cardiac surgery has rarely been undertaken in 0 pseudoxanthoma elasticum, although triple coro- $\omega$ nary artery bypass grafting has been performed in an 18 year old girl with a seven year history of angina $\stackrel{\circ}{C}$ pectoris. ${ }^{13}$ We believe that our case is the first in $\stackrel{D}{\oplus}$ which relief of a restrictive cardiomyopathy by lim- $\stackrel{+}{-}$ ited resection of the calcified bands has been $\frac{T}{3}$ attempted. The duration of such palliation cannot be $\frac{\vec{D}}{\mathrm{D}}$ certain but in the medium term relief of symptoms $\stackrel{\odot}{\Phi}$ has been good. A Carpentier-Edwards mitral het- $\varrho$ erograft was initially inserted in this case, in the 
hope that lifelong anticoagulant treatment could be avoided, because of the danger of gastrointestinal bleeding in this condition. Valvar heart disease such as mitral calcification, mitral and tricuspid valve stenosis, and aortic insufficiency, although rare, have all been reported. ${ }^{14}{ }^{15}$ It therefore seems likely that the rapid onset of heterograft calcification in our patient was directly related to the disease process. Thus despite the obvious risks of anticoagulation, a mechanical prosthesis is preferable to a heterograft.

\section{References}

1 Rigal D. Observation pour servir a l'histoire de la chéloìde diffuse xanthélasmique. Ann Derm Syph $1881 ; 2: 491-501$.

2 Huang SN, Steele HD, Kumar G, Parker RJO. Ultrastructural changes of the elastic fibres in pseudoxanthoma elasticum. Arch Pathol 1967;83:108-13.

3 Carlborg U, Ejrup G, Grönblad E. Vascular studies in pseudoxanthoma elasticum and angioid streaks. Acta Med Scand 1959;166:3-83.

4 Wilhelm K, Paver K. Sudden death in pseudoxanthoma elasticum. Med J Aust 1972;ii:1363-5.

5 Eddy DD, Farber EM. Pseudoxanthoma elasticum. Internal manifestations: a report of cases and a statistical review of the literature. Arch Dermatol 1962;86:729-40.

6 Carlborg U. Study of circulatory disturbances, pulsewave velocity, and pressure pulses in larger arteries in cases of pseudoxanthoma elasticum and angioid streaks. A contribution to the knowledge of the function of the elastic tissue and the smooth muscles in larger arteries. Acta Med Scand 1944;151:1-209.

7 Lebwahl MG, Distefano D, Prioleau PG, Uram M, Yannuzzi LAA, Fleischmajer R. Pseudoxanthoma elasticum and mitral valve prolapse. $N$ Engl J Med 1982;307:228-31.

8 Przybojewski JZ, Maritz F, Tiedt FAC, Van der Walt $\mathrm{JJ}$. Pseudoxanthoma elasticum with cardiac involvement. S Afr Med J 1981;59:268-75.

9 Balzer F. Recherches sur les caractères anatomiques du xanthélasma. Arch Physiol 1884;4:65.

10 Navarro-Lopez F, Llorian A, Ferrier-Roca O, Betriu A, Sang G. Restrictive cardiomyopathy in pseudoxanthoma elasticum. Chest 1978;78:113-5.

11 Przybojewski JZ, Daniels AR, Van der Walt JJ. Primary cardiac amyloidosis. S Afr Med $J$ 1980;57:774-80.

12 Voelkel G, Pietro DA, Folland ED, Fisher ML, Parisi AF. Echocardiographic features of constrictive pericarditis. Circulation 1978;58:871-5.

13 Bete JM, Banas JS Jr, Moran J, Pinn V, Levine HJ. Coronary artery disease in a 13 year old girl with pseudoxanthoma elasticum: successful surgical therapy. Am J Cardiol 1975;36:515-20.

14 McKusick VA. Inheritable disorders of connective tissue. 3rd ed. St Louis: CV Mosby, 1966:224-8.

15 Coffman JD, Summers SC. Familial pseudoxanthoma elasticum and valvular heart disease. Circulation 1959;19:242-50. 